\title{
True Knot of the Umbilical Cord-3D Power Doppler Imaging
}

\author{
Rajeev Choudhary $\cdot$ Sandeep Bajaj Choudhary
}

Received: 18 January 2015/ Accepted: 5 February 2015/Published online: 26 March 2015

(C) Society of Fetal Medicine 2015

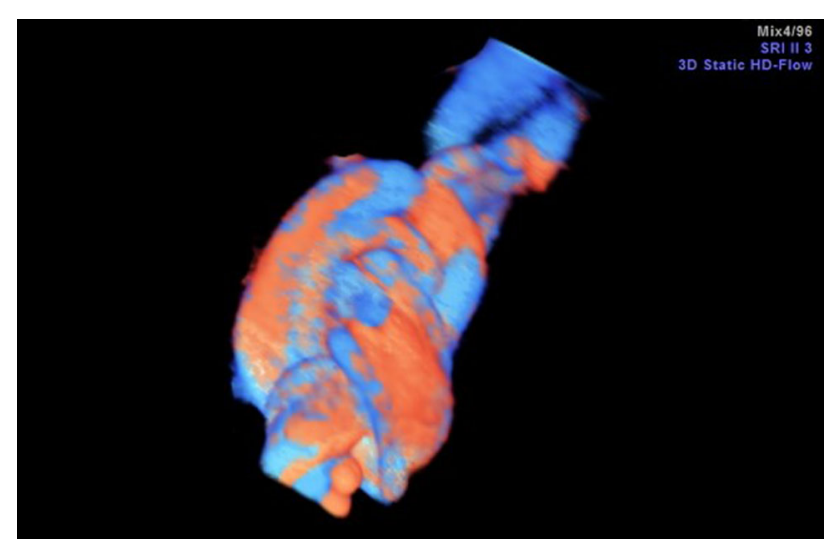

Fig. $13 D$ power Doppler angiogram showing true knot of the cord

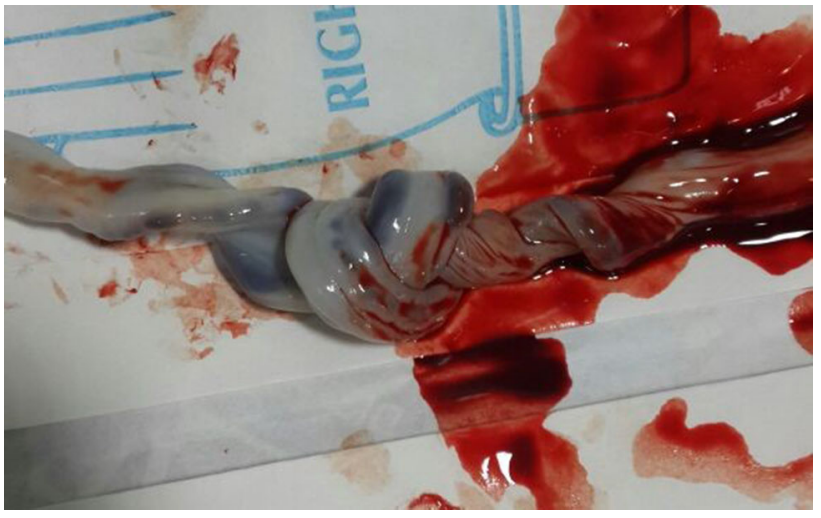

Fig. 2 True knot of the cord
A 30-year-old primigravida presented for ultrasound and Doppler evaluation for loss of fetal movements. The ultrasound showed a normal 36 weeks fetus with a single loop of nuchal cord, with umbilical artery and other Doppler flows within normal limits for gestational age. The liquor was adequate (deepest vertical pocket $-5 \mathrm{~cm}$ ). On tracing the cord for Doppler interrogation, a cross-section of the cord was seen surrounded by a complete loop of cord raising suspicion of a true knot of the cord. The suspicion was confirmed by acquiring three dimensional high definition power Doppler volume and rotating it along $\mathrm{x}$ and $y$ axis and displaying it in angiographic and glass body modes [1, 2] (Fig. 1). The fetus was delivered two days later by cesarean section for nonreassuring heart rate, and a

R. Choudhary $(\bowtie) \cdot$ S. B. Choudhary

Centre for Fetal Medicine, Dr Rajeev's Ultrasound Lab, B-15,

Shankar Garden, Vikas Puri, New Delhi 110018, India

e-mail: dr_rajeevchoudhary@yahoo.com healthy male fetus weighing $2510 \mathrm{~g}$ was delivered. The true knot of the cord was confirmed at $20 \mathrm{~cm}$ from the placental end of a $64 \mathrm{~cm}$ long cord (Fig. 2). True knot of the cord is relatively rare and is found in $0.3-2.1 \%$ of pregnancies [3] but is important to diagnose as it is associated with a fourfold increase in fetal death rate, nonreassuring heart rate patterns, and cesarean delivery. Other factors associated with true knot of the cord include polyhydramnios, gestational diabetes, male fetus, amniocentesis, long cord and small fetus [3].

Notching in the umbilical artery waveform has been demonstrated and correlated with cord compression in fetuses with true knot of the cord. Stenotic effect of the true knot on umbilical venous blood flow was demonstrated by Gembruch et al. in a mid-trimester ultrasound [4, 5]. Prenatal diagnosis of true umbilical cord knot has been random and the true impact of this condition on neonatal outcomes is yet to be evaluated. However, prenatal diagnosis of true knot of umbilical cord should warrant closer 
monitoring of the pregnancy and Doppler flow patterns [1]. Overdiagnosis of true knot when a tortuous or hypercoiled cord is visualized, should be avoided by carefully following the course of the cord and realtime visualization of the change in the cord position and course with fetal movements. Visualization of a complete loop around a cut section of the cord is the first sign, that raises suspicion which needs to be demonstrated consistently and confirmed on Doppler and 3D power Doppler angiographic images in the correct planes $[1,2]$.

Conflict of Interest None.

\section{References}

1. Abuhamad A. Three-dimensional ultrasound with color Doppler imaging of an umbilical cord true knot. Ultrasound Obstet Gynecol. 2014;43:360.
2. Rodriguez N, Angarita AM, Casasbuenas A, Sarmiento A. Three dimensional high-definition flow imaging in prenatal diagnosis of a true umbilical cord knot. Ultrasound Obstet Gynecol. 2012;39:245-6.

3. Hershkovitz R, Silberstein T, Sheiner E, Shoham-Vardi I, Holcberg G, Katz M, et al. Risk factors associated with true knots of the umbilical cord. Eur J Obstet Gynecol Reprod Biol. 2001;98:36-9.

4. Gembruch U, Baschat AA. True knot of the umbilical cord: transient constrictive effect to umbilical venous blood flow demonstrated by Doppler sonography. Ultrasound Obstet Gynecol. 1996;8:53-6.

5. Aranyosi J, Major T, Fulesdi B, Zatik J. Fetal arterial redistribution indicating true umbilical cord knot. Eur J Obstet Gynecol Reprod Biol. 2003;106:225-6. 